\title{
IMPLEMENTATION OF MANAGERIAL INNOVATIONS IN RUSSIA: DECISIONS' BACKGROUND, MAJOR AREAS AND FREQUENCY
}

\author{
Natalia Guseva ${ }^{1}$ \\ Yaroslav Sovetkin ${ }^{2}$
}

DOI: https://doi.org/10.31410/LIMEN.2020.261

\begin{abstract}
Unpredictable, complex and ambiguous business environments compel local and multinational companies to be more flexible and innovative in managerial practices. Nowadays managerial innovations (MI) are becoming a prevailing research area in management worldwide. This study investigates the key aspects of MI implementation in Russia from theoretical and empirical perspectives. The empirical study involved 1025 employees from 791 companies operating in Moscow and the Moscow region as the major business centers of Russia. The results showed that companies operating in the Russian market base their decision to implement MI mostly on "proprietary investigation" (29\% respondents). It was revealed that the major areas of MI implementation for such companies are "motivation" and "effective communication", which are part of the "soft managerial practices". Finally, the results of the study showed that in the majority of companies operating in the Russian market, the implementations of MI are made occasionally, without a systematic approach (39\% respondents).
\end{abstract}

Keywords: Implementation of managerial innovations, Key aspects of managerial innovations, Implementation process, Management innovations, Managerial innovations process, Russian companies, Multinational companies.

\section{INTRODUCTION}

$\mathrm{N}$ owadays the academic community devotes close attention to the research of managerial innovations' implementation process (Khosravi, Newton, Rezvani, 2019; Zhang, Khan, 2019; Guzman, Espejo, 2019, etc.). Heij and Volberda state that management innovations are "a key moderator in explaining firms' effectiveness in transforming R\&D into successful product innovation" (Heij, Volberda, 2019, p. 277).

The analysis of literature on managerial innovations based on the Scopus database showed a significant publication increase throughout the last decade (fig. 1). This increase is mainly driven by publications based research done in the US, China and the UK - the most dynamic economies in the world.

1 National Research University Higher School of Economics, 20 Myasnitskaya ulitsa, Moscow 101000 Russia

2 National Research University Higher School of Economics, 20 Myasnitskaya ulitsa, Moscow 101000 Russia 
Figure 1. Number of publications on the topic of managerial innovations: SCOPUS database, 2000-2019
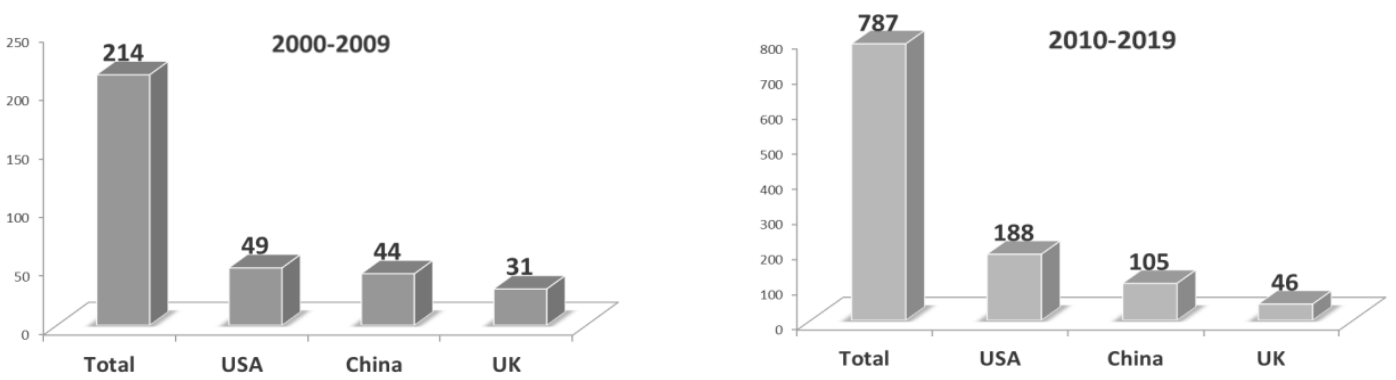

The definition of "managerial innovation" was firstly proposed by Kimberly as "any program, product or technique, which represents a significant departure from the state of the art of management at the time it first appears and which affects the nature, location, quality, or quantity of information that is available in the decision-making process" (Kimberly, 1981, p. 86). Hamel proposed a simple but precise definition: "management innovation changes how managers do what they do" (Hamel, 2006, p. 75).

A theoretical overview of related studies published during the last five decades allows to highlight two main processes of managerial innovations:

1. The process of MI generation (Burns, Stalker, 1961; Duncan, 1976; Van de Ven, 1986; Roberts, 1988; Miron, Erez, Naveh, 2004; Damanpour, Schneider, 2006; Damanpour, Aravind 2011; Batkovskiy, Kalachikhin, Semenova, Telnov, Fomina, 2016; Omelchenko, 2017; Khosravi, Newton, Rezvani, 2019),

2. The process of MI implementation (Van de Ven, 1986; Roberts, 1988; Damanpour, 1991; Miron, Erez, Naveh, 2004; Damanpour, Aravind, 2011; Batkovskiy, Kalachikhin, Semenova, Telnov, Fomina, 2016; Omelchenko, 2017; Khosravi, Newton, Rezvani, 2019).

Within the framework of this paper, the authors investigate the process of MI implementation through its key aspects such as: decision's background and major areas and frequency of MI implementation. The object of the study are MNCs and domestic companies operating in Russia.

The article is structured in five sections. The first section presents the theoretical background of MI implementation process. In the second section, methodology and empirical databased are described. Key aspects of the MI implementation process analysis among multinational and domestic companies operating in Russia are given within the third section. The fourth part shows research strengths and further directions for MI implementation. The last section describes the most significant peculiarities of the MI implementation process among companies operating in the Russian market, showing the major outcomes of conducted research.

\section{THEORETICAL BACKGROUND}

The theoretical framework of this study is based on the three-stage bibliographic analysis of scientific literature:

Step 1. By using keywords such as "Innovation", "Management innovation", "Managerial Innovation", articles with the highest citation index within databases "Web of Science" and 
"Scopus" were selected. The sampling period was not restricted. Key words have been selected based on the authors' perception.

Step 2. By using keywords "Organizational innovation", "Administrative innovation", "Innovation diffusion", "Innovation Implementation" articles with the highest citation index within databases "Web of Science" and "Scopus" were selected. The sampling period was not restricted as well. Keywords have been selected based on the analysis of the articles from stage 1.

Step 3. By using keywords from stages 1 and 2, articles throughout period from 2014 to 2019 with the highest citation index within databases "Web of Science" and "Scopus" were selected. As a result, 140 scientific publications were identified and analyzed for the period from 1975 to 2019 , covering citation indexes from 0 to 12476 within the "Web of Science" citation database and from 4 to 2185 within the "Scopus" database (fig. 2).

Figure 2. Distribution of identified scientific publications by year

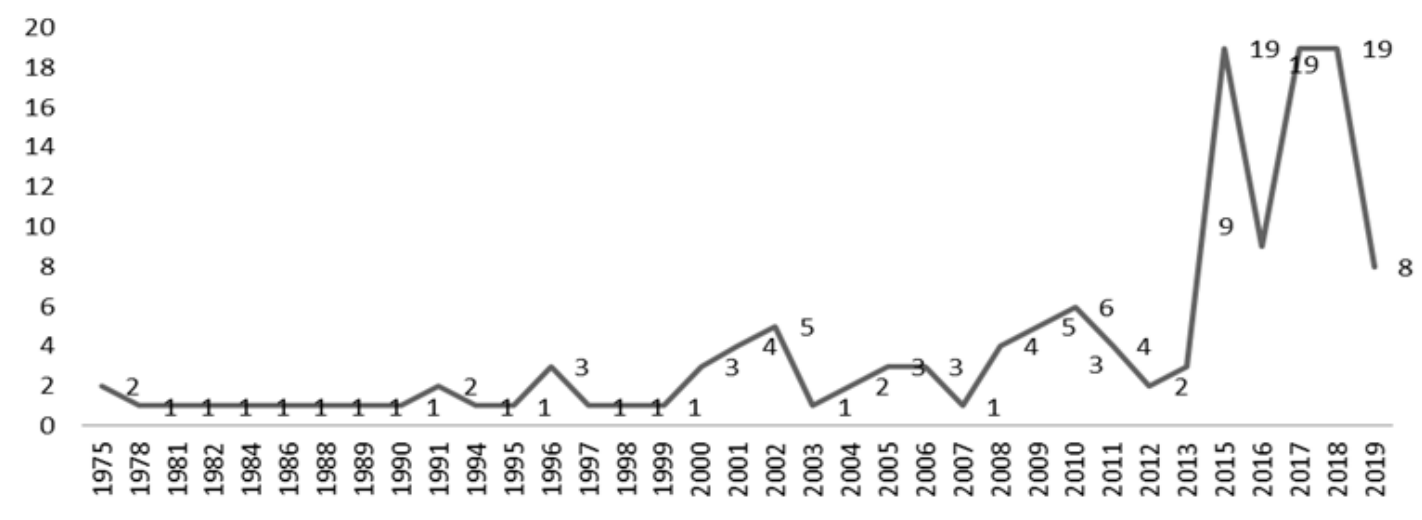

The conducted theoretical research has revealed two main components of MI term definitions detected in scientific sources:

- New managerial practices, processes, structures or techniques for the organization (Kimberly, 1981; Damanpour, Evan, 1984; Grebnev, 1985; Abrahamson, 1996; Titov, 1998; McCabe, 2002; Birkinshaw, Mol, 2006; Hamel, 2006; Hamel, Breen, 2007; Birkinshaw, Hamel, Mol, 2008; Walker, Damanpour, Aravind, 2011; Damanpour, Devece, 2011; Evans, 2013; Volberda, Van den Bosch, Heij, 2013; Zhang, Khan, 2019; Ceptureanu 2019; Khosravi, Newton, Rezvani, 2019; Wang, Zatzick, 2019; Janka, Heinicke, Guenther. 2019),

- Further organizational goals (Hamel, Breen, 2007; Birkinshaw, Hamel, Mol, 2008; Chechurina, 2010; Damanpour, Aravind, 2011; Safiulin, Maratkanova, 2011; Vaccaro, Jansen, Van Den Bosch, Frans, 2012; Volberda, Van den Bosch, Heij, 2013; Evans, 2013; Fartash, Davoudi, Baklashova, 2018; Zhang, Khan, 2019; Cho, Lee, Shin, 2019).

Within the framework of this research, it is proposed to use the latest definition of managerial innovations as the process of implementation of management practices, processes, structures and techniques, which are new to the subject of implementation, defined by the level of analysis. The peculiarities of the developed definition in comparison to the existing understanding of managerial innovations are based on the exclusion of the two following components:

- creation of something new to the state of the art,

- advancement of organizational targets. 
The first exclusion is based on the understanding that the newness of MI is a subjective characteristic of the innovation itself, depending on the level of analysis. A similar position is presented by Guzman and Espejo, who distinguished the managerial innovation process on business units' (BU) level and pointed out that newness was the MI characteristic towards a specific BU (Guzman, Espejo, 2019).

The argument for the second exclusion is that the advancement or the underachievement of organizational targets is the result of the MI implementation processes, which depends not only on MI per se but also on numerous other factors such as the external environment, motivation of employees, current priorities in organizational objectives etc. In this regard, including this component in the MI definition would associate the concept of managerial innovations with results of its implementation, which appears wrong. This position is related to the opinion mentioned in certain articles where the complexity of the MI implementation process and ambiguousness of its results are highlighted (Teece, 1980; Birkinshaw, Hamel, Mol, 2008).

The conducted theoretical overview allows emphasizing two consequential sub-processes of the MI implementation process:

1. The process of decision-making for the use of MI (Zaltman, Duncan, Holbek, 1973; Daft, 1978, Angle, Van de Ven, 2000; Damanpour, Schneider, 2006; Damanpour, Aravind, 2011; Omelchenko, 2017; Chung, Choi, 2018),

2. Implementation of MI per se (Daft, 1978; Klein, Sorra, 1996; Angle, Van de Ven, 2000; Damanpour, Schneider, 2006; Damanpour, Aravind, 2011; Omelchenko, 2017; Chung, Choi, 2018).

The second sub-process of MI implementation per se is the major research interest for this paper. Damanpour and Schneider state that decision making for MI implementation is finished when top managers decide to go ahead with the new idea and allocate resources to it (Damanpour, Schneider, 2006, p. 219). Conversely, the implementation in their opinion requires cooperation and commitment from non-managers (Damanpour, Schneider, 2006). Such position seems to be a development of the innovation implementation process described by Daft, who states that freedom and exposure of employees at lower organizational levels enable innovative ideas to enter the organization and be put forward. The leader role is to set innovation goals, encourage innovation initiatives from lower-level employees, and approve or disapprove innovation proposals (Daft, 1978, p. 194).

\section{METHODOLOGY AND DATABASE OF THE EMPIRICAL RESEARCH}

Based on the results of the theoretical research, the authors consider the implementation of MI as a decision-making process for the adaptation and direct application of new management practices, approaches, processes and techniques within the organization. As the key aspects of MI implementation, the authors highlight the background for decision-making, areas of its implementation and frequency of MI implementation. These aspects characterize the major peculiarities of MI implementation process for companies operating in the Russian market.

Three research questions have been developed:

RQ 1: What is the background for decision-making of managerial innovations' implementation?

RQ 2: What are the major areas of managerial innovations' implementation?

RQ 3: What is the frequency of managerial innovations' implementation? 
In order to answer these research questions, the empirical study has been conducted in 20192020 involving 791 companies operating in Moscow and the Moscow region being the major business centers in Russia (fig 3). Quantitative methods such as employee surveys have been used to gather the data (fig 4).

Figure 3. Companies' profile involved in the research
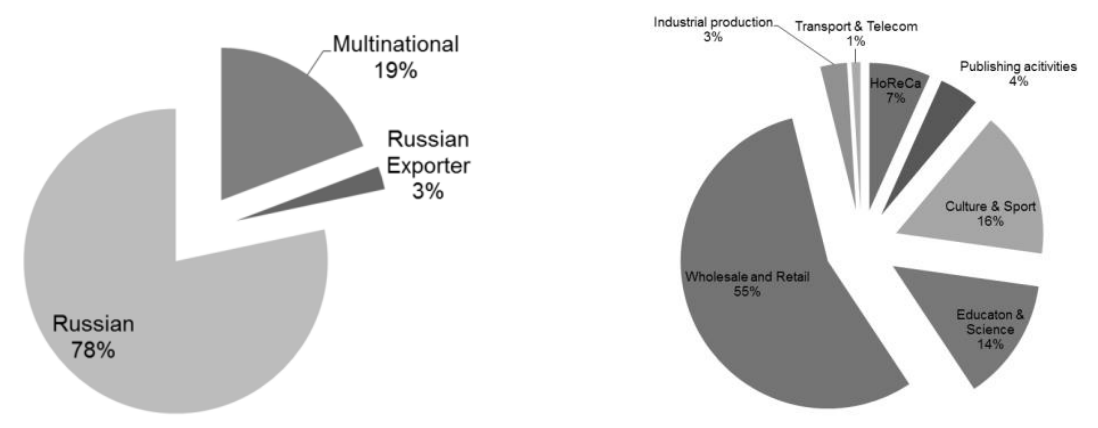

Figure 4. Employees' profile by job position and age
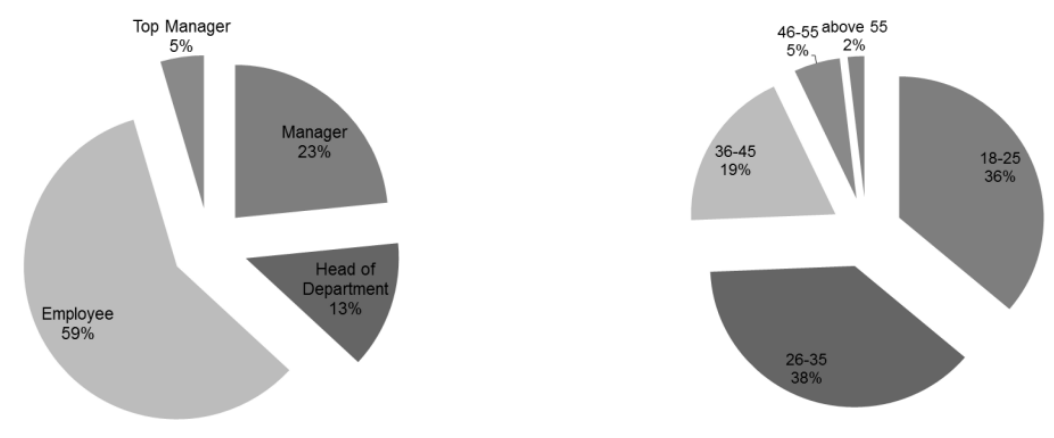

\section{RESEARCH FINDINGS}

The first part of the empirical research was focused on the background for decision-making of managerial innovations implementation (RQ1). The results obtained revealed that global and domestic companies operating in the Russian market base their decision to implement MI on "proprietary investigation"- $29 \%$ respondents, "benchmarking of best management practices"- $22 \%$ and "consulting services advice"- 20\% (fig. 5). "Pilot usage" appears as the least significant reason for MI implementation decision-making among companies operating on the Russian market (12\% respondents). Obtained data demonstrates that in the decisionmaking process related to MI implementation global and domestic companies rely mostly on their own experience and resources. As for the interaction with the external business environment, it is mostly limited to local companies' cooperation and usage of consulting services. Lack of widespread practices of interaction between Russian and multinational companies limits the understanding of world's best practices in terms of MI implementation, which slows down the development of modern managerial practices in Russia. Very low significance of pilot usage as a background for MI implementation decision-making could be explained by the observation that Russian companies are more likely to implement the entire innovation or not to implement it at all. Such "all or nothing" approach increases the risks and impedes the process of MI implementation. Decisions made in this way affect the whole company or at least its significant part, which forces managers to perform a comprehensive analysis of MI implementation outcomes. 
Figure 5. Background for decision-making of MI implementation for global and domestic companies operating in the Russian market

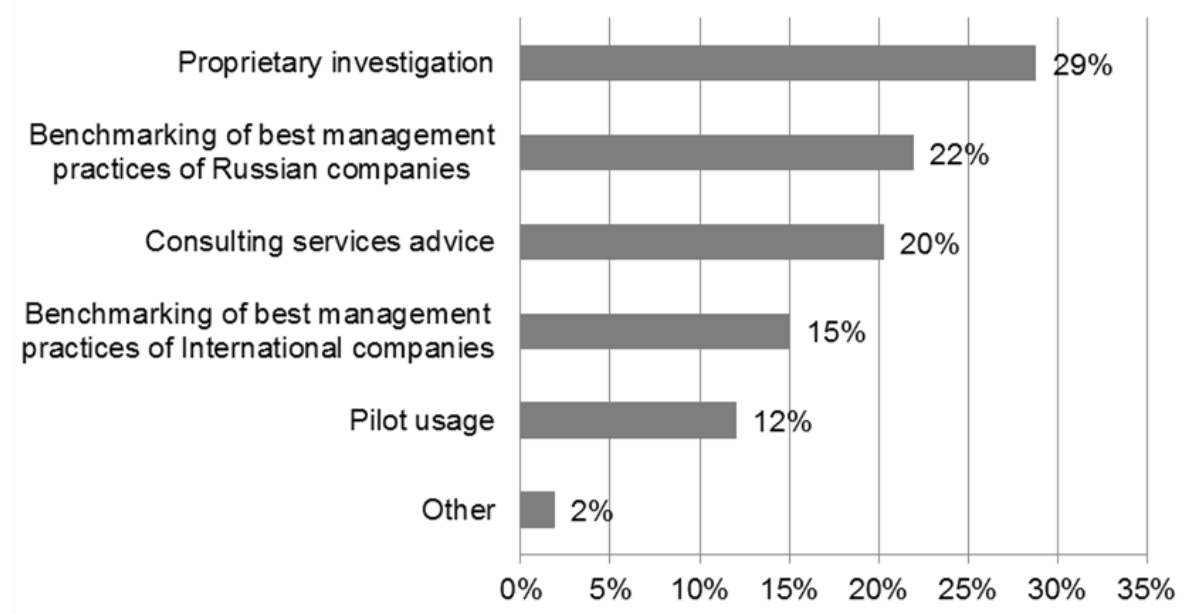

Based on the gathered data an inverse correlation between grounding the decision for MI implementation on "consulting services advice" and on "pilot usage" was observed (Pearson's index $-0,72)$. This finding shows that pilot-usage reduces the necessity for external validation of decisions made, forming individual understanding of new managerial approaches and practices being implemented. In this respect pilot-usage as a background for MI implementation decision-making can not only leverage the risks of this process, but decrease requirements for external validation as well, which could be directly reflected on costs reduction.

Areas of managerial innovations implementation (RQ2) were the focus of the second part of the conducted empirical research. Motivation (20\%) and efficient communication (18\%) were found to be the major areas for MI implementation (fig. 6).

One of the main findings of this section was that companies operating in the Russian market focus more on motivation and internal communications, which belong to "soft managerial practices". In this regard, two special aspects could be highlighted:

1. Customer experience and process management are important, but not the most significant areas of MI implementation for companies operating in the Russian market,

2. There is a lack of attention to managerial innovations in the negotiation process among companies, operating in the Russian market.

Figure 6. Areas of managerial innovations implementation for global and domestic companies operating in the Russian market

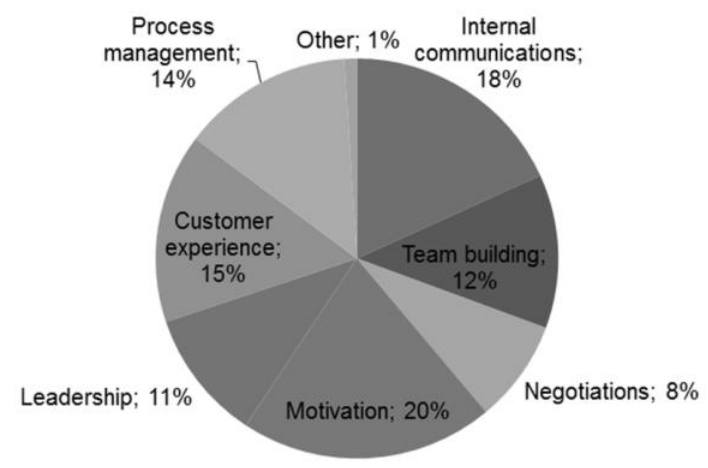


These arguments highlight the finding that managers in Russian companies remain uninterested in the use of modern management technologies in commercial processes, such as customer experience and negotiations. This situation can generate significant obstacles for business development within competitive markets and business segments.

Frequency of managerial innovations implementation (RQ3) was analyzed in the third part of the empirical research.

Analysis of acquired data revealed that for majority of companies operating in the Russian market implementations of MI are made occasionally and "without systematic approach"- 39\% respondents (fig. 7).

Figure 7. Frequency of managerial innovations implementation in global and domestic companies operating in the Russian market

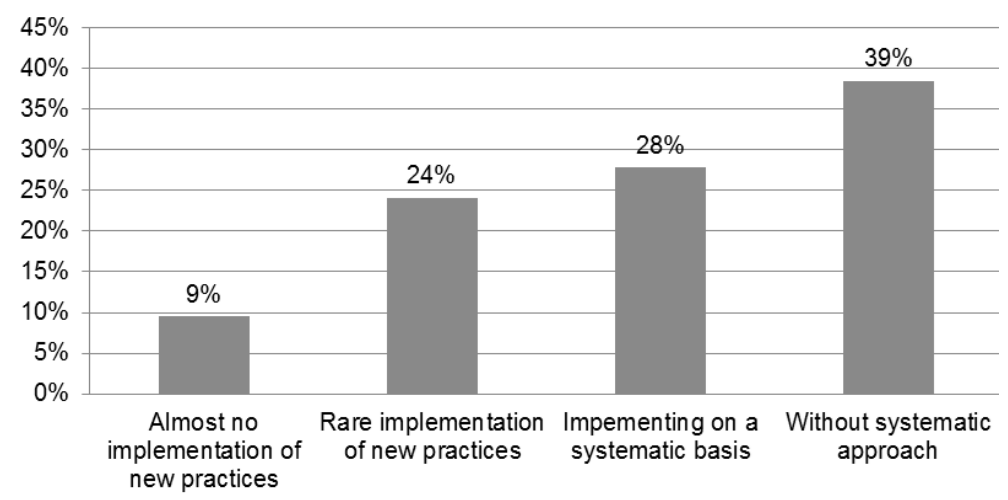

Despite of the majority of Russian companies implementing MI without a systematic approach, a significant part of respondents mentioned the implementation being done on a systematic basis (28\% of respondents) and nearly the same importance was shown for the answer "rare implementation of new practices" ( $24 \%$ of respondents). This data demonstrates contradictory trends in implementation of managerial innovations among companies operating in the Russian market, where the share of companies implementing new practices on a regular basis and the one with rare implementation are nearly identical. It is also worth mentioning that the lowest significance was observed for the answer "almost no implementation of new practices" ( $9 \%$ of respondents), which confirms the readiness of the overwhelming majority of companies operating in Russia to implement new managerial approaches and practices., However, implementations are mostly made occasionally and without a systematic approach for the time being.

\section{FUTURE RESEARCH}

The conducted research has some limitations that present opportunities for future studies on the MI implementation topic. The first research trajectory is the comparison of decisionmaking backgrounds, areas and frequency of managerial innovations implementation between different types of companies. The second trajectory is related to the application of the casestudy method for best MI implementation practices.

The study also entails practical implications. Global and domestic companies operating in the Russian market can compare their approach to MI implementations in terms of decision's background, major areas and frequency. Such comparison can provide insights for the development of strategic capabilities for successful operation in Russian market. 


\section{CONCLUSION}

This research focuses on the key aspects of MI implementations in Russia from theoretical and empirical perspectives.

The theoretical framework was based on the analysis of 140 scientific publications for the past 45 years with high citation indexes within "Web of Science" and "Scopus" databases. The authors considered the implementation of MI as a decision-making process for the adaptation and direct application of new management practices, approaches, processes and techniques within the organization. The decision background, areas and frequency of MI implementation were selected as key research questions for the MI implementation study.

Seven interesting findings emerge from the empirical part of the research, which was based on the survey of 1,025 employees from 791 companies operating in Moscow and the Moscow region:

- Companies operating in the Russian market base their decisions related to managerial innovations implementation mostly on proprietary investigation (29\% of the respondents);

- The absence of widespread interaction practices between Russian and multinational companies limits the understanding of world's best practices in terms of MI implementation, which impedes development of modern managerial practices in Russia.

- Very low significance of pilot usage as a background for MI implementation decisionmaking (12\% of the respondents) shows that Russian companies are more likely to implement the innovation entirely or not to implement it at all. Such approach increases the risks and slows down the process of MI implementation. Decisions made in this way affect the whole company or at least its significant part, which forces managers to make a comprehensive analysis of MI implementation outcomes.

- Pilot-usage requires less external validation for the decision-making. In this respect pilotusage as a background for MI implementation decision-making can not only leverage the risks of this process, but also decrease a necessity for external validation, which could be directly reflected on costs reduction.

- The major areas of MI implementation among companies operating in the Russian market are motivation and effective communication $(20 \%$ and $18 \%$ of the respondents respectively), which belongs to the "soft managerial practices" category.

- Managers of Russian companies remain uninterested in the use of modern management skills such as negotiations (8\% of the respondents), which could create significant problems for business development within competitive markets and business segments.

- The majority of companies implement new managerial approaches and practices occasionally, without a systematic approach.

- Finally, managers could use key findings and practical implications presented in this article to gain new insights on the strategic capabilities' development.

\section{REFERENCES}

Daft, R. L. (1978). A dual-core model of organizational innovation. Academy of Management Journal, 21 (2): 193-210.

Damanpour, F., Schneider, M. (2006). Phases of the adoption of innovation in organizations: Effects of environment, organization, and top managers. British Journal of Management, 17 (3): 215-236. 
Hamel, G. (2006). The why, what and how of management innovation. Harvard Business Review, 84 (2): 72-84.

Heij, C.V., Volberda, H.W., Van den Bosch, F.A.J. (2019). How to leverage the impact of $\mathrm{R} \& \mathrm{D}$ on product innovation? The moderating effect of management innovation. $R$ and $D$ Management, 50 (2): 277-294.

Kimberly, J.R. (1981) Managerial Innovation. In: Nystrom, P.C. and Starbuck, W.H., Eds., Handbook of Organizational Design, Oxford University Press, New York, Vol. 1, 84104. 